The cholinergic drug pilocarpine may cause sweating and salivation, nausea, vomiting and diarrhoea, and bronchospasm.

Finally, any mydriatic at all used by a casualty officer in an unconscious patient will produce a severe systemic adrenergic reaction-in the neurologist or neurosurgeon who receives the patient. The casualty officer should never forget that the size and reactions of the pupils are important in the management of patients in coma, with head injuries, or with many other neurological diseases.

Professor of Ophthalmology,

C I PHILlips

University of Edinburgh,

Princess Alexandra Eye Pavilion,

Edinburgh EH3 9HA

1 Smith SE. Mydriatic drugs for routine fundal inspection. A reapraisal. Lancet 1971;ii:837-9. Apt L, Henrick A. Pupillary dilatation with single eye drop mydriatic combinations. Am $\mathcal{J}$ Ophthalmol 1980;89:553-9.

${ }^{3}$ Mapstone R. Safe mydriasis. Br f Ophthalmol 1970;54:690-2.

Becker B, Shaffer RN. Diagnosis and therapy of the glaucomas. 2nd ed. St Louis: C V Mosby Co, 1965:149-50.

${ }_{6}^{5}$ Mapstone R. Dilating dangerous pupils. Br $\mathcal{f}$ Ophthalmol 1977;61:517-24

Saheb NE, Lorenzetti D, East D, Salpeter-Carlton S. Thymoxamine versus pilocarpine in the reversal of phenylephrine-induced mydriasis. Can f Ophthalmol 1982;17:266-7.

${ }^{7}$ Davidson SI. Systemic effects of eye drops. Trans Ophthalmol Soc UK 1974;94(part II):487-95.

${ }^{8}$ Meyer SM, Fraunfelder FT. Phenylephrine hydrochloride. Ophthalmology 1980;87:1177-80.

Brown MM, Brown GC, Spaeth GL. Lack of side-effects

${ }^{10}$ Davidson SI. Drug interactions in ophthalmology. Trans Ophthalmol Soc UK 1975 .95 (part II) 277 80.

${ }^{11}$ Asher R. A taste of Asher. London: Keynes Press, 1983:23.

\section{Autoimmune thyroid disease and pregnancy}

The care of a woman with autoimmune thyroid disease who becomes pregnant presents two problems: the effect which the maternal disease may have on the fetus and newborn, and the influence which pregnancy itself may have on the maternal disease.

A successful normal pregnancy assumes the adjustment of the mother's immune system to an antigenically foreign fetoplacental unit. For reasons still uncertain the maternal immune response is generally suppressed progressively through pregnancy. 1 This is manifested by a decreased blastogenic response of mitogen stimulated lymphocytes, a fall in the serum concentration of the IgG immunoglobulins, and alterations in the numbers of peripheral blood $\mathrm{T}$ lymphocyte series variably reported as an increase in suppressor $\mathrm{T}$ cells or a decrease in helper $\mathrm{T}$ cells. Though such changes seem unlikely to reflect primary events, the factors responsible remain to be determined. One possibility is that fetal suppressor $\mathrm{T}$ cells or their soluble products may help modulate the maternal immune response.

Against that background, how does pregnancy affect autoimmune thyroid disease? In normal pregnancy maternal IgG crosses the placenta and is detectable in the fetal and neonatal circulation, where it provides a protective mechanism until the neonate can generate his own IgG response to foreign challenge. Since maternal IgG crosses the placenta any autoantibodies of this immunoglobulin subclass will do likewise. Several thyroid autoantibodies can influence fetal and neonatal thyroid function. In hyperthyroid Graves' disease antibodies to the thyrotrophin receptor stimulate thyroid function. ${ }^{2}$ Such antibodies may persist even after thyroidectomy or treatment with radioiodine. If present in high titre in the third trimester of pregnancy ${ }^{3}$ they may stimulate the fetal thyroid and cause intrauterine hyperthyroidism. ${ }^{45}$ If the mother is receiving an antithyroid drug such as carbimazole this may also cross into the fetus and prevent hyperthyroidism-but the active immunoglobulin may persist for a month or two in the child's circulation and then cause a self limiting neonatal hyperthyroidism. This condition requires treatment with antithyroid drugs. ${ }^{6}$

More recently blocking antibodies interacting with the thyrotrophin receptor have been recognised in autoimmune thyroid disease. These antibodies block the action of thyrotrophin on the thyroid and so can be responsible for hypothyroidism in some patients with myxoedema and Hashimoto's disease. During pregnancy such antibodies cross the placenta and are one cause, albeit rare, of intrauterine and neonatal hypothyroidism; this remits spontaneously as the maternal immunoglobulins disappear from the child's circulation. ${ }^{7}$ Combinations of stimulating and blocking antibodies may interact with the fetal and neonatal thyroid, and-depending on their affinities and relative titres-lead to varying alterations of thyroid function-for example, hypothyroidism progressing to hyperthyroidism, which then remits. ${ }^{89}$

The clinical message is that serum concentrations of thyrotrophin receptor antibodies should be checked in the third trimester of pregnancy in all women with autoimmune thyroid disease-namely, Graves' disease, Hashimoto's disease, and myxoedema. Several assays are available, but the most convenient and widely available is that depending on the inhibition of labelled thyrotrophin binding to solubilised thy otrophin receptors by the receptor antibodies. ${ }^{10}$ Children born to mothers with high titres of thyrotrophin receptor antibody are at risk of developing one of the neonatal thyroid syndromes.

Pregnancy also has profound effects on the autoimmune thyroid diseases. Studies from both Japan and Norih America have shown changes in clinical thyroid state and in biochemical and serological measurements during pregnancy and after birth. In a study of 41 pregnancies in 35 patients with Graves' disease in remission Amino et al showed recurrence of disease in early pregnancy and after delivery and amelioration in the latter half of pregnancy. ${ }^{11}$ They had previously shown a fall in circulating concentrations of thyroglobulin and microsomal antibodies during pregnancy followed by rises post partum in patients with Graves' disease and autoimmune thyroid disease. ${ }^{12}$ Similar changes in antibody concentrations have been seen in pregnancies in normal women. ${ }^{13}$ In the United States Turney et al found postpartum thyroid disease, usually autoimmune, in $9 \%$ of 238 women. ${ }^{14}$ Likewise, Amino and his colleagues found that $5.5 \%$ of 507 postpartum Japanese women had transient hyperthyroidism or hypothyroidism three to eight months after delivery. ${ }^{15}$ No similar studies have been reported from Britain. Postpartum autoimmune thyroid disease has distinctive characteristics: a high frequency of previous goitre; early (at less than four months) goitre or hyperthyroidism or both, and later (over four months) hypothyroidism, sometimes in the same patients; a return to euthyroidism five to 10 months post partum associated with decrease in size but occasional persistence of the goitre; and increasing titres of thyroid microsomal antibodies, peaking at three to four months. ${ }^{16}$

The basis of postpartum hyperthyroidism remains uncertain. A few patients appear to have Graves' disease with an increased radioiodine uptake by the thyroid, but most show the suppressed uptake of the postpartum painless thyroiditis with transient thyrotoxicosis-the PPTT syndrome described by Ginsberg and Walfish. ${ }^{17}$ Whether this syndrome is autoimmune or viral is still unknown, though it is very similar to 
if not identical with the painless thyroiditis occurring apart from pregnancy, which makes up at least $10 \%$ of all cases of hyperthyroidism in North America. ${ }^{1819}$ The histological appearances of the thyroid and serological changes favour an autoimmune origin, a view supported by the association of the syndrome with HLA-DR3 (as seen in Graves' disease and atrophic thyroiditis) and HLA-DR5 (as seen in Hashimoto's disease). ${ }^{20}$ Plainly patients with postpartum thyroid dysfunction go unrecognised, though sporadic cases of transient hypothyroidism are now being seen in Britain. Their clinical implications are uncertain; the condition is often self limiting, but it may herald later, more overt manifestations of thyroid disease. Certainly psychiatric disorders such as postpartum psychoses have been reported in some affected patients. ${ }^{15}$

Systematic epidemiological studies of the prevalence of postpartum thyroid disease are now required in Britain and in Europe. If these show that postpartum thyroid disorders arise largely from the pool of asymptomatic women with thyroid antibodies then screening for such antibodies might be added to the routine tests performed in early pregnancy. Sensitive, robust, and automated assay systems for thyroid antibodies-for example, ELISA (enzyme linked immunosorbent assays)-are now readily available. ${ }^{21}$ Awareness of the risk to the fetus and neonate of transplacentally derived thyroid antibodies should now allow recognition and early treatment of the rare neonatal thyroid syndromes.

Alan M McGregor Wellcome senior fellow and honorary consultant physician Reginald Hall Professor of medicine

Welsh National School of Medicine, Cardiff CF4 4XN

Colin Richards Consultant obstetrician

Caerphilly District Miners' Hospital, Caerphilly

1 Gall SA. Maternal adjustments in the immune system in normal pregnancy. Clin Obstet Gynecol 1983;26:521-36.

${ }^{2}$ Adams DD. Thyroid-stimulating autoantibodies. Vitam Horm 1980;38 119-203.

${ }^{3}$ Munro DS, Dirmikis SM, Humphries H, Smith T, Broadhead GD. The role of thyroid stimulating immunoglobulins of Graves's disease in neonatal thyrotoxicosis. Br f Obstet Gynaecol 1978;85:837-43.

' McKenzie JM, Zakarija M. Pathogenesis of neonatal Graves' disease. $\mathcal{F}$ Endocrinol Invest 1978;2:183-9.

${ }^{5}$ Zakarija M, McKenzie JM. Pregnancy-associated changes in the thyroidstimulating antibody of Graves' disease and the relationship to neonatal hyperthyroidism. F Clin Endocrinol Metab 1983;57:1036-40.

${ }^{6}$ Hollingsworth DR. Graves' disease. Clin Obstet Gynecol 1983 ;26:615-34.

Matsuura N, Yamada Y, Nohara Y, et al. Familial neonatal transient hypothyroidism due to maternal TSH-binding inhibitor immunoglobulins. $N$ Engl f Med $1980 ; 303: 738-41$.

${ }^{*}$ Hoffman WH, Sahasrananan P, Ferandos SS, Burek CL, Rose NR. Transient thyrotoxicosis in an infant delivered to a long-acting thyroid stimulator (LATS) - and LATS protector negative, thyroid-stimulating antibody-positive woman with Hashimoto's thyroiditis. $\mathcal{F}$ Clin Endocrinol Metab 1982;54:354-6.

${ }^{9}$ Zakarija M, McKenzie JM, Munro DS. Immunoglobulin G inhibitor of thyroid-stimulating antibody is a cause of delay in the onset of neonatal Graves' disease. $\mathcal{F}$ Clin Invest 1983;72:2352-6.

10 Shewring G, Smith BR. An improved radioreceptor assay for TSH receptor antibodies. Clin Endocrinol (Oxf) 1982;17:409-17.

"Amino N, Tanizawa A, Mori $\mathrm{H}$, et al. Aggravation of thyrotoxicosis in early pregnancy and after delivery in Graves' disease. $\mathcal{F}$ Clin Endocrinol Metab 1982;55:108-12.

${ }^{12}$ Amino N, Kuro E, Tanizawa O, et al. Changes of serum anti-thyroid antibodies during and after pregnancy in autoimmune thyroid diseases. Clin Exp Immunol 1978;31:30-7.

${ }^{13}$ D'Armiento M, Salabe H, Vetrano G, Scucchia M, Pathi A. Decrease of thyroid antibodies during pregnancy. $\mathcal{F}$ Endocrinol Invest 1980;4:437-8.

${ }^{14}$ Turney S, Nikolai T, Roberts R. The prevalence and clinical course of post-partum lymphocytic thyroiditis. In: Proceedings of 63rd annual meeting of the American Endocrine Society, San Francisco, 1982. (Abstract 557.)
${ }^{15}$ Amino N, Mori H, Iwatani Y, et al. High prevalence of transient postpartum thyrotoxicosis and hypothyroidism. $N$ Engl F Med 1982;306: 849-52.

${ }^{16}$ Amino N, Miyai K. Post-partum autoimmune endocrine syndromes. In: Davies TF, ed. Autoimmune endocrine disease. New York: J Wiley and Sons, 1983:247-72.

${ }^{17}$ Ginsberg J, Walfish PG. Post-partum transient thyrotoxicosis with painless thyroiditis. Lancet 1977 ; i:1125-8.

18 Woolf PD. Transient painless thyroiditis with hyperthyroidism: a variant of lymphocytic thyroiditis ? Endocr Rev 1980;1:411-20.

${ }^{19}$ Levine SN. Current concepts of thyroiditis. Arch Intern Med 1983; $143: 1952-6$.

${ }^{20}$ Farid NR, Hawe BS, Walfish PG. Increased frequency of HLA-DR3 and 5 in the syndromes of painless thyroiditis with transient thyrotoxicosis: evidence for an autoimmune aetiology. Clin Endocrinol (Oxf) 1983;19:699-704.

${ }^{21}$ Weetman AP, Rennie DP, Hassman R, Hall R, McGregor AM. Enzymelinked immunoassay of monoclonal and serum microsomal autoantibodies. Clin Chim Acta 1984 ;138:237-44.

\section{Economic appraisal}

Over a decade ago Cochrane adopted an arresting antithesis as the title for his Rock Carling lecture-Effectiveness and Efficiency. These words have now become commonplace in the language of health service management and politics but they are often misunderstood by clinicians. Efficiency at a technical level is a relatively simple concept and is to do with the use of facilities. The need for it can hardly be disputed, though clinicians vary widely in their enthusiasm for pursuing goals such as maximising patient flow through investigations, beds, and operating theatres. The recently introduced term "efficacy," promoted by the Office of Technology Assessment in Washington, describes safety and benefit in a pilot studywhen committed clinicians promoting an innovation use it on selected patient populations. Effectiveness is now usually restricted to benefit accruing when the application is more widespread-but people differ about its meaning. For some effectiveness relates to benefit under average conditions of use-the drug, technology, or service is robust enough to survive without the commitment and ideal environment of the early evaluators. For others it means that benefit has been shown in the community as a whole, which is related also to the prevalence of patients likely to benefit and to the availability of the technology. By this latter definition effectiveness requires more than clinical evaluation even when this is done in a variety of circumstances.

Clinicians are also often confused about cost effectiveness and cost benefit. It does not help that cost effective analysis is to do with technical efficiency: the least costly means of achieving a specified beneficial end-for example, is dialysis or transplantation the better treatment for end stage renal disease? Cost benefit analysis is about allocative efficiency: whether it is better to use resources in one way than anotherfor example, to relieve renal disease or heart disease. It is therefore about ends not means. Clinicians readily accept the principle of cost effective analysis, but they are usually less happy about cost benefit analysis because this requires an explicit evaluation of benefits. Such a comparison calls for a monetary value to be ascribed not only to material benefits such as earning capacity but also to gains such as years of quality adjusted life, the relief of pain, or the resolution of anxiety and uncertainty. Ascribing values to such intangibles calls for judgment, and clinicians may disagree about the values. But the advantage of requiring such an attempt when comparing benefits is that it then becomes clear how much 